\title{
Effects of reporting associative strategies on the retention of paired-associates'
}

\author{
FREDERIC J. BOERSMA, RODNEY C. CONKLIN AND JAMES E. CARLSON
}

UNIVERSITY OF ALBERTA, EDMONTON

The present study examined the effects on long term retention of reporting associative strategies after learning. Ss learned $10 \mathrm{~L}-\mathrm{H}$ paired associate items to a criterion of two perfect, consecutive trials per item. Retention measures were collected after $20 \mathrm{~min}$., $48 \mathrm{hr}$. and 7 days. Ss reporting associative strategies had higher retention scores than those not reporting such mediational links, and this superiority increased with increments in the delay interval. The results were discussed in terms of an overlearning-postorganizer paradigm.

The importance of mediational links in pairedassociate learning has been well documented. Experimenters have shown that number of trials, number of errors or time to criterion are significantly reduced when mediational links are employed during learning (Jensen \& Rohwer, 1963a, b; Spiker, 1960), and also, that retention is enhanced (Wallace, Turner, \& Perkins, 1957). Usually effects of mediational links are studied by varying task instructions, or by providing Ss with specific aids prior to learning. Recently several studies have shown that mediational links can also be reliably examined by studying verbal reports collected at the conclusion of a learning task (Farber, 1963; Eagle \& Leiter, 1964; Martin, Boersma, \& Cox, 1965; Underwood \& Schulz, 1960). The effects on long term retention of reporting associative strategies (mediational links) after learning, however, have not been investigated.

The primary purpose of this study was to examine the effects on long term retention of reporting associative strategies after learning. A secondary purpose was to see whether the findings reported by Martin et al (1965) would replicate using a different experimental procedure and more meaningful material.

\section{Method}

One hundred and twenty educational psychology undergraduates, 60 males and 60 females, served as Ss in the experiment. They were presented individually with a paired-associate learning task consisting of ten pairs of low-high meaningful items selected from Noble's (1952) list: NEGLAN-LEADER, SAGROLEMONEY, TAROP-DINNER, LATUK-OFFICE, MEARDON-INSECT, VOLVAP-JEWEL, ZUMAP-KENNEL, BODKIN-WAGON, ATTAR-CAPTAIN, FLOTSAMUNCLE.

The items were typed in $3 / 16$ in. capital letters on $5 \times 8$ blank cards. Learning and test trials were presented in different random orders at a 3 sec. rate; the intertrial interval was $10 \mathrm{sec}$. An oral recall procedure was employed for test trials. All Ss were required to learn each item to a criterion of two perfect, consecutive trials, and once an item was responded to correctly twice in a row it was removed from the list.

Retention measures were collected under two experimental conditions, with and without strategy reports being collected at the conclusion of the learning task, and for three delay intervals: $20 \mathrm{~min} ., 48 \mathrm{hr} ., 7$ days. Each cell contained $20 \mathrm{Ss}, 10$ males and 10 females. A 2 by 3 by 2 factorial design was used in the study. At the conclusion of the learning session Ss in strategy treatments were again shown each pair. But now they were given up to $60 \mathrm{sec}$. to report in writing how they attempted to form each association. Ss required approximately 30-45 sec. to report a strategy. A non-verbal intelligence test was presented between strategy reports and retention measures for the two 20 min. delay groups in an attempt to minimize confounding rehearsal effects. A recall procedure, similar to that used for test trials, was employed for the retention task. But now Ss were given $10 \mathrm{sec}$. per item to write down their response. After retention data were collected, Ss in both the strategy and non-strategy treatments were asked to express in writing how they initially attempted to learn each pair.

The verbal reports were categorized according to the scheme developed by Martin et al(1965). The reliability of the classifications was checked by having three judges independently rate a random sample of 60 stategies, one strategy per $\mathrm{S}$, obtained at the conclusion of the learning task. The coefficient of concordance $(W=.94)$ indicated high agreement between the independent ratings.

\section{Results and Discussion}

The analysis of total number of trials to criterion revealed no statistically significant differences between treatment groups. A significant sex factor, however, was found $(p<.05)$. More specifically, the data indicated that groups were similar in learning ability, but that females reached criterion in fewer trials than males.

Figure 1 shows retention curves for strategy and non-strategy treatments. In brief, it shows that $\mathrm{Ss}$ encouraged to report associative strategies retained more than those who were not, and that the effect became greater as delay increased. The interpretation is supported by an analysis of variance on total retention scores. The analysis revealed statistically significant treatment (strategy, non-strategy) and delay (20 min., $48 \mathrm{hr} ., 7$ days) effects $(p<.001)$, and a significant interaction between these variables $(p<.001)$. A test of simple main effects showed no significant differences 


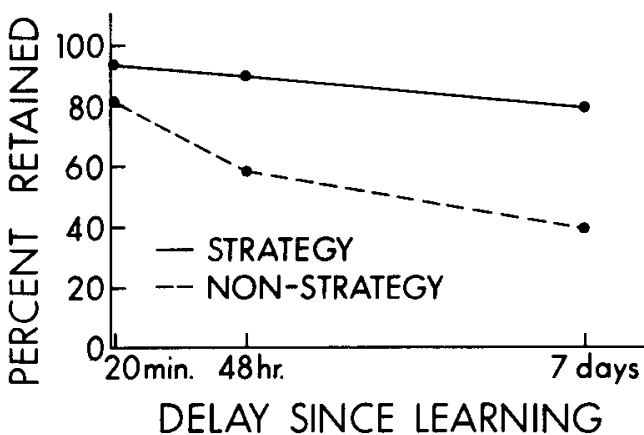

Fig. 1. Percent retention curves for strategy and non-strategy treatments.

between delay periods for strategy treatments, but that significant differences existed between delay periods for non-strategy treatments. Further analysis, using the Newman-Keuls technique (Winer, 1962,p. 239), revealed that all three non-strategy means were significantly different from each other $(p<.01)$. Significant differences were also obtained between strategy and nonstrategy treatment means for $48 \mathrm{hr}$. and 7 day delay conditions $(\mathrm{p}<.001)$.

Verbal reports were classified according to the seven category rank-ordered scheme developed by Martin et al (1965). For strategy treatments, 93\% used similar strategies after $20 \mathrm{~min} ., 82 \%$ after $48 \mathrm{hr}$. and $83 \%$ after 7 days. The Pearson correlation coefficient between total strategy scores reported after learning and after retention was .914 . A t-test between means for total strategy scores collected after retention revealed no statistically significant differences between strategy and non-strategy treatments. In short, the data indicated that all groups used similar associative strategies during acquisition, and that these strategies, for the most part, were retained over the delay intervals.

Contrary to the findings of Martin et al, a significant Spearman correlation between total strategy and acquisition scores was not obtained, nor was there any statistically significant relationship between amount retained and strategy level employed during learning. These findings may be attributed, in part, to the fact that the present study ran each $S$ to a criterion of two perfect trials per item, a procedure which tended to truncate acquisition scores, whereas Martin et al used number correct in ten trials. Another difference between the two studies is that the present study used $\mathrm{L}-\mathrm{H}$ items and not L-L items. The use of more mean- ingful material resulted in greater usage of superordinate $(\mathbf{4 5} \%)$ strategies than reported by Martin et a1 (29\%). It appears that variability within strategy scores was restricted by this increase in meaningfulness of items. In any case, the data suggest that method and type of material may affect the increasing relationship between strategy level and learning efficiency previously reported.

The retention findings may be due, in part, to overlearning since Ss in strategy treatments were exposed on the average $30-45 \mathrm{sec}$. longer to each item than Ss in non-strategy treatments. The data suggests, however, that overlearning is not the only factor contributing to greater retention scores for strategy treatments. For example, the present study found no significant drop in retention scores over time for the three strategy treatments, a finding inconsistent with retention data in general, and overlearning retention curves in particular. Thus, it appears that the verbalizing of mediational links after learning forced Ss to actively conceptualize (post-organize) acquisition strategies, and that this effect operated in addition to overlearning to further strengthen the S-R association. Additional research is now needed to provide further support for this hypothesis. More specifically, research must extract effects of overlearning from post-organizing.

\section{References}

Eagle, M., \& Leiter, E. Recall and recognition in intentional and incidental learning. J. exp. Psychol., 1964, 68, 58-63.

Farber, I. E. The things people say to themselves. Amer. Psychologist, 1963, 18, 185-197.

Jensen, A. R., \& Rohwer, W. D., Jr. The effect of verbal mediation on the learning and retention of paired-associates by retarded adults. Amer. J. ment. Defic., 1963a, 68, 80-84.

Jensen, A. R., \& Rohwer, W. D., Jr. Verbal mediation in pairedassociate and serial learning. J. verbal Learn. verbal Behav., $1963 \mathrm{~b}, 1,346-352$.

Martin, C. J., Boersma, F. J., \& Cox, D. L. A classification of associative strategies in paired-associate learning. Psychon. Sci., 1965, 3, 455-456.

Noble, C. E. An analysis of meaning. Psychol. Rev., 1952, 59, 421-430.

Spiker, C. C. Associative transfer in verbal paired-associate learning. Child Develpm., 1960, 31, 73-87.

Underwood, B. J., \& Schulz, R. W. Meaningfulness and verbal learning. New York: J. B. Lippincott, 1960, 296-305.

Wallace, W. H., Tumer, S. H., \& Perkins, C. C. Preliminary studies of human information storage, Project No. 132C, 1957, Institute for Cooperative Research, University of Pennsylvania.

Winer, B. J. Statistical principles in experimental design. New York: McGraw-Hill, 1962.

\section{Note}

1. This research was supported in part by A.A.C.E.R. Grant 11365 . 